\title{
GESTÃO AMBIENTAL DE AGROTÓXICOS NA SEGURANÇA DO TRABALHADOR E DO MEIO AMBIENTE
}

\author{
Maria Aparecida Peres de Oliveira ${ }^{1}$ \\ Edna Maria Bonfim da Silva ${ }^{2}$ \\ Tonny Jose Araujo da Silva ${ }^{3}$ \\ Cassia Sgobi Zanchi ${ }^{4}$ \\ Jaqueline Valeria Rodrigues de Sousa ${ }^{5}$ \\ Vinicius Melo da Silva ${ }^{6}$
}

\section{INTRODUÇÃO}

A região Centro-Oeste ocupa a primeira posição em produção de grãos (CONAB, 2017). O Estado de Mato Grosso deve seguir na liderança da produção nacional, representando $27,4 \%$ do total no País (IBGE, 2017). Os diversos tipos de agrotóxicos têm como função principal combater pragas, doenças e plantas daninhas que acometem os cultivos.

Atuam como substâncias químicas que têm uma atividade biológica inerente: podem afetar outros organismos vivos que não são o alvo original do tratamento. São substancias importantes para a proteção das lavouras, mas é preciso cuidado e consciência no uso de uma forma geral, para segurança do trabalhador no campo e do meio ambiente.

Além de cumprirem o papel de proteger as culturas, podem oferecer riscos à saúde humana e ao ambiente. A falta de conhecimento e o uso incorreto de agrotóxicos oferece riscos como a contaminação dos solos agrícolas, das águas superficiais e subterrâneas, dos alimentos, riscos de efeitos negativos em organismos

1 Professora Dra. Rondonópolis. UFMT. mapeoli@gmail.com.

2 Professora PhD. Rondonópolis. UFMT.

3 Professor PhD. Rondonópolis. UFMT.

4 Graduanda Zootecnia. Rondonópolis. UFMT.

5 Mestranda Engenharia Agrícola. Rondonópolis/UFMT

6 Doutorando da Universidade Federal de Viçosa.UFV. 
terrestres e aquáticos além de intoxicação humana pelo manuseio, consumo de água e alimentos contaminados, bem como o risco de intoxicação ocupacional de trabalhadores e produtores rurais.

\section{Classificação dos agrotóxicos}

Os agrotóxicos são conhecidos por diversos nomes, dentre eles, praguicidas, produtos fitossanitários, pesticidas, defensivos agrícolas, venenos, biocidas, mas o termo correto no Brasil, de acordo com a Lei Federal no 7.802/89, é agrotóxico. São divididos em classes, onde a classificação sera por finalidade de uso, e é definida pelo poder de ação do ingrediente ativo sobre organismos-alvo, como inseticidas, fungicidas, herbicidas, acaricidas, reguladores, inibidores de crescimento, etc. As classes mais utilizadas são de herbicidas, os inseticidas e os fungicidas. Vários estudos demonstram que os inseticidas são os principais causadores das intoxicações humanas ocorridas no campo.

Essa lei define os agrotóxicos e afins como produtos e componentes de processos físicos, químicos ou biológicos destinados ao uso dividido em duas categorias: agrícolas e não agrícolas, distribuídos nos setores de produção, armazenamento e beneficiamento de produtos agrícolas, nas pastagens, na proteção de florestas nativas ou implantadas e de outros ecossistemas, bem como em ambientes urbanos, hídricos e industriais, cuja finalidade seja alterar a composição da flora e da fauna, a fim de preservá-la da ação danosa de seres vivos considerados nocivos. Só poderão ser produzidos, exportados, importados, comercializados e utilizados, se previamente registrados em órgão federal, cujos registros são concedidos pelo Ministério da Agricultura, Pecuária e Abastecimento/MAPA, atendidas as diretrizes e exigências dos Ministérios da Saúde e Agencia Nacional de Saude/ Anvisa e Ministério do Meio Ambiente/IBAMA).

Para serem vendidos ou expostos à venda em todo o território nacional, os agrotóxicos e afins são obrigados a exibir rótulos próprios e bulas, redigidos em português, que contenham, entre outros, os seguintes dados (A lei Federal 9974/00):

\section{I - indicações para a identificação do produto \\ II - instruções para utilização}


III - informações relativas aos perigos potenciais, compreendidos: saúde do homem, animais e meio ambiente

IV - recomendação para que o usuário leia o rótulo antes de utilizar o produto.

De acordo com essa mesma Lei, as responsabilidades administrativa, civil e penal pelos danos causados à saúde das pessoas e ao meio ambiente, quando da produção, comercialização, utilização, transporte e destinação de embalagens vazias de agrotóxicos, seus componentes e afins. O não cumprimento das legislações vão de multas até reclusão.

Existem normas usuais para a nomenclatura, a quais são:

NOME COMUM (ABNT 14725-1): uso internacional, são neologismos formados artificialmente, válidos quando aprovados por entidades oficialmente credenciadas.

NOME QUÍMICO (ABNT 14725-1): expressão da fórmula estrutural.

NOME COMERCIAL OU DE FANTASIA: nome dado pelo fabricante, que tem grafia própria e é propriedade particular do registrante. O nome comercial é registrado no Ministério da Agricultura, para comercialização no país. Normalmente é identificado pelo símbolo ${ }^{\circledR}$ à direita e acima do nome. Exemplo: Roundup ${ }^{\circledR}$.

Critérios para criação do nome comum: fácil pronúncia em qualquer língua. Não se assemelhar a palavras em qualquer língua. Não conflitar com marcas em qualquer país. Desejável alguma relação com o nome químico.

\section{Risco e classificação toxicológica}

Durante o uso de agrotóxicos a exposição deve ser evitada, pois o risco potencial à saúde não depende apenas da toxicidade, mas também da exposição. Quanto menor a exposição, menor o risco. Risco: é a probabilidade de um evento nocivo ocorrer por conta da exposição a um agente químico. Na caracterização do risco o que se faz é a comparação dos resultados da exposição com os dados dos efeitos adversos sobre os organismos considerados. Um procedimento simples para integrar ambos (exposição e perigo) é o Método do Quociente, no qual divide-se a concentração ambiental estimada (CAE) pelo dado toxicológico agudo ou crônico. O Quo- 
ciente de Risco (QR) obtido é então comparado ao nível aceitável e ao nível crítico. Dependendo das condições da exposição ou da dose, toda substância tem potencial de ser tóxica (Figura 1).

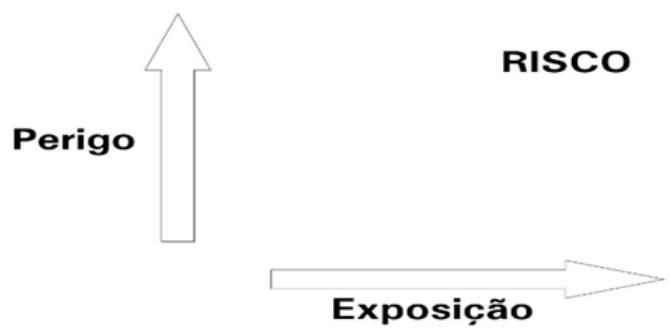

Figura 1. Representação esquemática do risco como função da exposição e do perigo (efeito adverso).

Fonte: Embrapa 2017.

Enquanto a embalagem de um produto fitossanitário está fechada e lacrada, ele não apresenta risco significativo de contaminação, pois não há exposição. Quando a embalagem é aberta, os riscos podem ser grandes e algumas regras básicas de segurança devem ser seguidas para evitar a exposição:

- Ler cuidadosamente as instruções do rótulo e/ou bula do produto antes da aplicação;

- Usar os equipamentos de proteção individual recomendados;

- Verificar a calibragem do equipamento aplicador usando apenas água;

- Observar se o equipamento aplicador possui vazamentos e elimine-os antes de preparar a calda;

- Misturar a quantidade certa de produto para preparar a calda que será usada no tratamento; 
- Fazer a lavagem das embalagens vazias (quando necessário) enquanto estiver preparando a calda;

- Escolher as horas mais frescas do dia para realizar a pulverização (abaixo de $30 \circ$ C); e

- Não aplicar o produto na presença de ventos fortes ou na ausência de ventos (ideal: entre 4 e $10 \mathrm{~km} \backslash \mathrm{h}$ ), para evitar a deriva.

- Escolher preferencialmente a umidade relativa do ar em torno de $30 \%$.

\section{Saúde e segurança do trabalhador}

O Brasil tem liderado o ranking dos principais consumidores de agrotóxicos. Esse uso está relacionado à atual política agrícola do país, adotada a partir de 1960, com a Revolução verde, que representou a mudança tecnológica no sistema produtivo, visando aumentar a produção agrícola com intuito de acabar com a fome no mundo (KOOP et al., 2013). Os agrotóxicos são um dos recursos mais utilizados pelos produtores rurais para tentar compensar a perda de produtividade (VEIGA, 2007), porem, muitas vezes, essa utilização é feita de maneira e em quantidades inadequadas, sem o conhecimento das reais necessidades do solo, das plantas e principalmente sem os devidos cuidados de segurança de trabalho, acarretando em efeitos negativos a saúde e ao meio ambiente. A relação entre agricultura e saúde pública sempre foi muito grande, seja na função de supridora de alimentos, seja pelos riscos à saúde humana e ao meio ambiente causados pela utilização de agrotóxicos.

Em 2013, o Ministério do Trabalho criou a Norma Regulamentadora de Segurança e Saúde no Trabalho na Agricultura, Pecuária, Silvicultura, Exploração Florestal e Aqüicultura, a NR no 31, a qual estabelece os preceitos a serem observados na organização e no ambiente de trabalho, em qualquer atividade da agricultura, incluindo as atividades industriais desenvolvidas no ambiente agrário. A NR no 31 deixa claro os procedimentos e exigências a serem atendidas com relação ao uso de agrotóxicos na agricultura tanto por parte do empregador como dos empregados.

A segurança do trabalho é um conjunto de medidas técnicas, administrativas, educacionais, médicas e psicológicas para prevenir 
acidentes nas atividades laborais. Medidas que têm por finalidade evitar a criação de condições inseguras e corrigi-las, quando existentes nos locais ou meios de trabalho, bem como preparar as pessoas para a prática de prevenção de acidentes. Não basta fornecer, é preciso fiscalizar o uso dos equipamentos de proteção individual (EPIs), que são todo dispositivo ou produto, de uso individual pelo trabalhador, destinado à proteção contra riscos e ameaças a sua segurança e a sua saúde.

A principal medida é minimizar a exposição do trabalhador, que pode ocorrer de diversas formas. O Ministério do Trabalho estabelece os preceitos a serem observados na organização e no ambiente de trabalho, em qualquer atividade da agricultura, incluindo as atividades industriais desenvolvidas no ambiente agrário. O empregador rural ou equiparado deve fornecer instruções aos que manipulam agrotóxicos, adjuvantes e afins, e aos que desenvolvam qualquer atividade em áreas onde possa haver exposição direta ou indireta a esses produtos, garantindo os requisitos de segurança previstos em norma.

\section{Vias de intoxicação}

As principais vias de exposição aos agentes químicos no homem são: dérmica (pele, boca e mucosas), inalatória (trato respiratório inalação de partículas ou vapores durante manuseio e aplicação), ocular (olhos) ou oral (trato gastrointestinal). Ao abrir as embalagens, aplicar os produtos ou limpar os equipamentos de aplicação, o aplicador deve sempre utilizar luvas, respiradores e outros EPIs, com o objetivo de evitar a exposição do organismo ao produto tóxico.

\section{Uso de Equipamento de Proteção Individual - EPI}

Em todos os segmentos de trabalho em que as atividades oferecem algum risco ao operador, existe a obrigação de uso de EPI. No manuseio dos produtos fitossanitários não é diferente, inclusive é lei e vale tanto para o empregado como para o empregador.

O uso do EPI na agricultura está inserido na Norma Regulamentadora - NR-31. A NBR 9735 regulariza o conjunto de equipa- 
mentos de emergência no transp. Terrestre de produtos perigosos. A obrigatoriedade do uso de EPI está amplamente contemplada em várias outras legislações que tratam do uso correto e seguro dos produtos fitossanitários:

- $\quad$ CLT - Prevê dispensa do trabalhador por justa causa pelo não uso do EPI;

- Lei no 7.802 - Ações cíveis contra o empregador, multas e indenizações pelo não fornecimento de EPI;

- Lei no 6.514 - regulamentada pela Portaria 86, de 3/3/2005, NR-31 - Define a relação Empregado-Empregador no meio rural, tornando claras as obrigações e responsabilidades de cada uma das partes. Diante da NR-31, somente estão aptos a manusearem agrotóxicos aqueles que receberem treinamento específico de 20 horas e que estejam com idade entre 18 e 60 anos. Não é permitido o manuseio de agrotóxicos por gestantes.

De modelo geral, a empresa é obrigada a fornecer aos empregados, gratuitamente, EPI adequado ao risco, em perfeito estado de conservação e funcionamento, nas seguintes circunstâncias: Sempre que as medidas de ordem geral não ofereçam completa proteção contra os riscos de acidentes do trabalho ou de doenças profissionais e do trabalho; Enquanto as medidas de proteção coletiva estiverem sendo implantadas; e Para atender a situações de emergência.

\section{Principais equipamentos de proteção}

Os EPIs não foram desenvolvidos para substituir os demais cuidados na aplicação e, sim, para complementá-los. Para reduzir os riscos de contaminação, as operações de manuseio e aplicação devem ser realizadas com cuidado, para evitar ao máximo a exposição.

O equipamento de proteção individual, de fabricação nacional ou importado, só poderá ser posto à venda ou utilizado com a indicação do Certificado de Aprovação (CA), expedido pelo órgão nacional competente em matéria de segurança e saúde no trabalho do Ministério do Trabalho e Emprego (MTE).

Conforme ABNT 9735, no caso de transporte, durante o treinamento, o transportador deve atender às orientações dos fabri- 
cantes do produto e do equipamento de proteção individual. 0 traje mínimo (calça comprida, camisa ou camiseta, com mangas curtas ou compridas e calçados fechados) não é considerado EPI, porém deve ser usado pelo motorista durante o trajeto e pelo pessoal envolvido (se houver) quando forem efetuar a avaliação da emergência e ações iniciais.

Segundo a NR31, é obrigação do empregador:

- Adquirir e fornecer EPIs adequados aos riscos de cada atividade;

- Orientar e treinar o trabalhador sobre o uso adequado, guarda e conservação;

- Exigir seu uso;

- Vedar o uso de roupas pessoais quando da aplicação de agrotóxicos;

- Fornecer ao trabalhador somente o equipamento aprovado pelo órgão nacional competente em matéria de segurança e saúde do trabalho;

- Fornecer EPI higienizado, bem como responsabilizar-se pela descontaminação deste ao final de cada jornada de trabalho;

- Substituir imediatamente o EPI, quando danificado ou extraviado, e;

- Comunicar ao MTE qualquer irregularidade observada.

O empregado também terá de observar as seguintes obrigações:

- Utilizar o EPI apenas para a finalidade a que se destina;

- Responsabilizar-se pela guarda e pela conservação;

- Comunicar ao empregador qualquer alteração que o torne impróprio ao uso, e;

- Cumprir as determinações do empregador sobre o uso pessoal.

Os equipamentos de proteção individual, além de essenciais à proteção do trabalhador, visando à manutenção de sua saúde física e proteção contra os riscos de acidentes do trabalho e/ou de doenças profissionais e do trabalho, podem também proporcionar a redução de custos ao empregador. 
Para a Justiça do Trabalho, o fato de comprovar que o empregado recebeu o equipamento (por meio de ficha de entrega de EPI) não exime o empregador do pagamento de uma eventual indenização, pois a norma estabelece que o empregador deva garantir o seu uso, com fiscalização e medidas obrigatórias, se for o caso.

Os tipos de EPI utilizados podem variar dependendo do tipo de atividade ou de riscos que poderão ameaçar a segurança e a saúde do trabalhador e da parte do corpo que se pretende proteger, tais como:

- Proteção auditiva: abafadores de ruídos ou protetores auriculares;

- Proteção respiratória: máscaras com filtro para vapores orgânicos e gases ácidos, combinado com filtro mecânico;

- Proteção visual e facial: óculos e viseiras;

- Proteção da cabeça: capacetes;

- Proteção de mãos e braços: luvas e mangotes;

- Proteção de pernas e pés: sapatos, botas e botinas, e;

- Proteção contra quedas: cintos de segurança e cinturões.

No caso do uso de agrotóxicos, os seguintes EPIs devem ser utilizados:

Luvas: equipamento de proteção muito importante, protege uma das partes do corpo com maior risco de exposição: as mãos. Existem vários tipos no mercado e a escolha deve levar em conta o tipo de formulação do produto a ser manuseado. Produtos que contêm solventes orgânicos como, por exemplo, os concentrados emulsionáveis, devem ser manipulados com luvas de borracha nitrílica ou neoprene, pois estes materiais são mais resistentes aos solventes orgânicos. Luvas de látex ou de PVC podem ser usadas para produtos sólidos ou formulações que não contenham solventes orgânicos. De modo geral, recomenda-se a aquisição das luvas de borracha NITRÍLICA ou NEOPRENE, materiais que podem ser utilizados com qualquer tipo de formulação.

Respiradores: geralmente chamados de máscaras, têm o objetivo de evitar a inalação de vapores orgânicos, névoas ou finas partículas tóxicas pelas vias respiratórias. Existem basicamente dois tipos de respiradores: sem manutenção (chamados de des- 
cartáveis), que possuem vida útil relativamente curta e recebem a sigla PFF (peça facial filtrante), e os de baixa manutenção, que possuem filtros especiais para reposição, normalmente mais duráveis. Os mais utilizados nas aplicações de produtos fitossanitários são os que possuem filtros P1 ou P2 (consulte o fabricante). Quando se manuseiam produtos que emitem vapores orgânicos ou cheiro forte, recomenda-se o uso de respiradores com filtro de carvão ativado. São equipamentos importantes, mas que podem ser dispensados em algumas situações, quando não há presença de névoas, vapores ou partículas no ar, por exemplo: aplicação tratorizada de produtos granulados incorporados ao solo; pulverização com tratores com cabines, etc. Devem estar sempre limpos, higienizados e seus filtros jamais devem estar saturados (difícil respiração ou passando cheiro). Antes do uso de qualquer tipo é necessário realizar o teste de ajuste de vedação para evitar a falha na selagem. Quando estiverem saturados, os filtros devem ser substituídos. É importante notar que, se utilizados de forma inadequada, os respiradores tornam-se desconfortáveis e podem transformar-se numa verdadeira fonte de contaminação.

Viseira facial: protege os olhos e o rosto contra respingos durante manuseio e aplicação. Deve ter a maior transparência possível e não distorcer as imagens. A tira de espuma no alto da viseira, além de absorver o suor da testa, também tem a função de evitar embaçamento. Precisa proporcionar conforto ao usuário e permitir o uso simultâneo do respirador, quando for necessário. Quando não houver a presença ou emissão de vapores no ar, o uso da viseira com o boné árabe pode dispensar o uso do respirador, aumentando o conforto do trabalhador. Existem algumas recomendações de uso de óculos de segurança para proteção dos olhos. A substituição dos óculos pela viseira protege não somente os olhos do aplicador, mas também o rosto.

Jaleco e calça hidro-repelentes: são confeccionados em tecido de algodão tratado para tornarem-se hidro-repelentes; são apropriados para proteger o corpo das névoas do produto formulado e não para conter exposições extremamente acentuadas ou jatos dirigidos. Os tecidos de algodão com tratamento hidrorepelente ajudam a evitar o molhamento e a passagem do produto tóxico para o interior da roupa, sem impedir a troca térmica, 
tornando o equipamento seguro e confortável. Eles resistem a aproximadamente 30 lavagens, se manuseados de forma correta (observe recomendações do fabricante). Os tecidos devem ser preferencialmente claros, para reduzir a absorção de calor, além de ser de fácil lavagem, para permitir sua reutilização. Há calças com reforço adicional nas pernas, que podem ser usadas nas aplicações em que houver alta exposição do aplicador à calda do produto ou desgaste mecânico (pulverização com equipamento manual, por exemplo).

Boné árabe: confeccionado em tecido de algodão tratado para tornar-se hidro-repelente. Protege o couro cabeludo e o pescoço contra a névoa da pulverização. Usado em combinação com a viseira, oferece excelente proteção dérmica, inalatória e ocular.

Avental: produzido com material resistente a solventes orgânicos (PVC, Bagum ou emborrachados), aumenta a proteção do aplicador contra respingos de produtos concentrados durante a preparação da calda e pode ser utilizado como capa em eventuais vazamentos de equipamentos de aplicação costal. Existem vários modelos: curtos, longos, de colheita, etc. Cada um atendendo a necessidades específicas.

Botas: devem ser preferencialmente de cano alto, impermeáveis e resistentes aos solventes orgânicos como, por exemplo, de PVC. Sua função é a proteção dos pés. Estão disponíveis em várias cores e modelos. Recomenda-se as brancas por absorverem menos calor.

\section{Recomendações e sequencia para vestir os EPIs}

Calça e jaleco: os EPIs devem ser usados sobre uma bermuda e camiseta de algodão, para aumentar o conforto. $O$ aplicador deve vestir primeiro a calça e, depois, o jaleco, ajustando-os perfeitamente. O velcro deve ser fechado. Caso o jaleco de seu EPI possua capuz, assegure-se de que este estará devidamente vestido, pois, caso contrário, ele facilitará o acúmulo e retenção de produto.

Botas: devem ser calçadas sobre meias de algodão, de cano longo, para evitar atrito com pés, tornozelos e canela. As bocas da calça do EPI devem sempre estar para fora do cano das botas, a fim de impedir o escorrimento do produto tóxico para o interior do calçado. 
Avental: deve ser utilizado na parte da frente do jaleco durante o preparo da calda e na parte de traz do jaleco durante as aplicações com equipamento costal. Para aplicações com equipamento costal, é fundamental que o pulverizador esteja funcionando bem, sem apresentar vazamentos.

Respirador: deve ser colocado de modo que os dois elásticos fiquem fixados corretamente e sem dobras; um fixado na parte superior da cabeça, e outro, na parte inferior, na altura do pescoço. $\mathrm{O}$ respirador deve encaixar-se perfeitamente na face do trabalhador, não permitindo abertura alguma para a entrada de partículas ou vapores. Para usar o respirador, o trabalhador deve estar sempre bem barbeado.

Viseira facial: deve ser ajustada firmemente na testa, mas sem apertar a cabeça do trabalhador. A viseira deve ficar um pouco afastada do nariz para não embaçar.

Boné árabe: deve ser colocado na cabeça sobre a viseira. 0 velcro do boné árabe deve ser ajustado sobre a viseira facial, assegurando que toda a face esteja protegida, assim como o pescoço e a cabeça.

Luvas: último equipamento a ser vestido, deve ser usado de forma a evitar o contato do produto com as mãos. As luvas devem ser colocadas normalmente para dentro das mangas do jaleco. Mas existe uma exceção, quando o trabalhador pulveriza dirigindo o jato para alvos que estão acima da linha de seu ombro (para o alto), as luvas devem ser usadas para fora das mangas do jaleco. $\mathrm{O}$ objetivo é evitar que o produto aplicado escorra para dentro das luvas e atinja as mãos (Figura 1). 

1. Calça
2. Jaleco
3. Botas
4. Avental
5. Respirador
6. Viseira facial
7. Boné árabe
8. Luvas

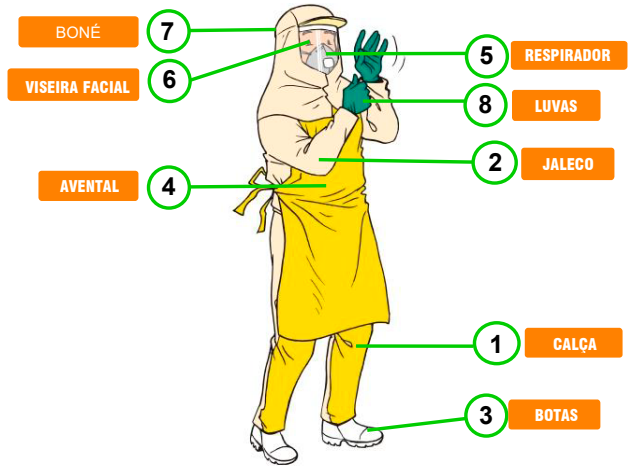

Figura 1. Sequência para vestir os EPIs

Fonte: Manual de Uso Correto de EPI - Andef. 2015.

\section{Recomendações para retirar os EPIs}

Após a aplicação, normalmente a superfície externa dos EPIs está contaminada. Portanto, na retirada dos equipamentos, é muito importante evitar o contato com o corpo do usuário. Antes de começar a retirá-los, recomenda-se que o aplicador lave as luvas vestidas. Isto facilitará a descontaminação das luvas e ajudará a reduzir riscos de exposição acidental (Figura 2).

Lave as luvas e as botas antes de retirar os EPIs:

1. Boné árabe

2. Viseira facial

3. Avental

4. Jaleco

5. Botas

6. Calça

7. Luvas

8. Respirador

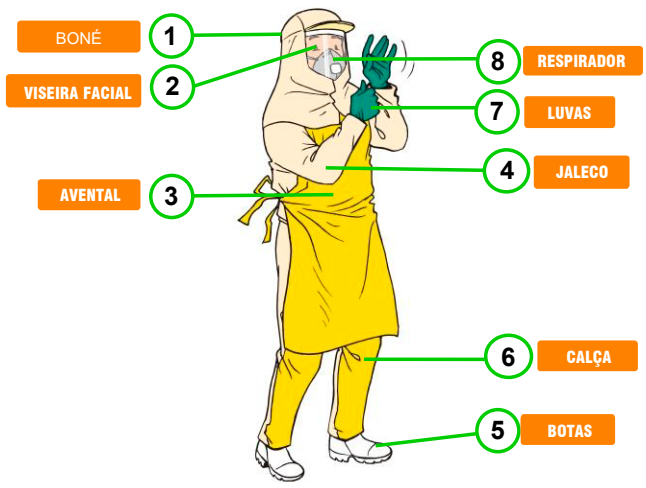

Figura 2. Sequência para retirar os EPIs

Fonte: Manual de Uso Correto de EPI - Andef. 2015. 


\section{Recomendação de manutenção dos EPIs}

- Segundo a NR-31, deve-se garantir que nenhum dispositivo de proteção ou vestimenta contaminada sejam levados para fora do ambiente de trabalho

- Os EPIs devem ser lavados separadamente das roupas da família, utilizando-se sabão neutro e água fria;

- Após secarem à sombra, os EPIs devem ser passados com ferro quente, a fim de revitalizar o tratamento do tecido;

- Mantenha-os em bom estado de conservação;

- Faça revisão periódica; se observar rasgo ou perceber que a hidro-repelência não está eficiente, descarte a vestimenta;

- Guarde-os em local separado, e;

- Substitua-os sempre que necessário.

\section{Embalagens, resíduos e descarte}

A preocupação em proteger o meio ambiente vem aumentando, principalmente no que diz respeito as atividades no campo. Neste contexto, surgiu o sistema Campo Limpo, do Instituto Nacional de Processamento de Embalagens Vazias/InpEV (INPEV, 2010), através da logística reversa de embalagens de agrotóxicos como elemento fundamental para os projetos do meio ambiente. Trata do fluxo reverso dos produtos e resíduos, enquanto a "logística tradicional" trata de processos de planejamentos, controle de fluxo, estoque de matérias primas, entre outros aspectos da produção (OLIVEIRA; SILVA, 2005). Lambert e Stock (1981 apud FELIZARDO; HATAKEYAMA, 2005) destacaram a logística reversa como produto seguindo na contramão de uma rua de sentido único pela qual a grande maioria dos embarques de produtos flui em uma direção. Leite (2009) define essa área como parte da logística empresarial que planeja, opera e controla o fluxo e as informações logísticas correspondentes, do retorno dos bens de pós-vendas e de pós-consumo ao ciclo de negócios ou ao ciclo produtivo, por meio dos canais de distribuição reversos, agregando-lhes valor de diversas naturezas: econômica, ecológica, legal, logístico, de imagem corporativa, entre outros. 
Desta forma, o inpEV traz um conjunto de legislação que norteia a destinação final das embalagens vazias de defensivos agrícolas, o qual compreende (INPEV, 2015): a Lei Federal $n^{\circ}$ 9.974/2000, que altera a Lei $n^{\circ} 7.802 / 1989$; Decreto Federal $n^{\circ} 4.074 / 2002$, que regulamenta a Lei $n^{\circ} 7.802 / 1989$; Decreto Federal $n^{\circ} 5.981 / 2006$, que dá nova redação e inclui dispositivos ao Decreto no 4.074/2002; entre outras, além de Leis e Decretos Estaduais; Resoluções do Concelho Nacional de Meio Ambiente (CONAMA) e da Agência Nacional de Transportes Terrestres (ANTT); Portaria do Instituto Brasileiro do Meio Ambiente e dos Recursos Naturais Renováveis (IBAMA) e várias Normas Técnicas.

Todos os usuários de agrotóxicos, seus componentes e afins deverão efetuar a devolução das embalagens vazias dos produtos aos estabelecimentos comerciais em que foram adquiridos, de acordo com as instruções previstas nas respectivas bulas, no prazo de até um ano, contado da data de compra, ou prazo superior, se autorizado pelo órgão registrante, podendo a devolução ser intermediada por postos ou centros de recolhimento, desde que autorizados e fiscalizados pelo órgão competente. Quando o produto não for fabricado no país, assumirá a responsabilidade a pessoa física ou jurídica responsável pela importação.

O Brasil é recordista mundial no recolhimento de embalagens de agrotóxicos. Nos últimos dez anos, o porcentual de embalagens plásticas colocadas no mercado que foram recolhidas pela indústria após o uso do produto nas lavouras atingiu 95\% (INPEv, 2016). Em 2016, 44.528 mil toneladas de embalagens vazias tiveram destino ambientalmente correto por meio do Sistema Campo Limpo, representando $94 \%$ do total das embalagens primárias comercializadas. $\mathrm{O}$ estado do Mato grosso teve um aumento de $0,9 \%$ na destinação correta das embalagens (total de 10.485 toneladas).

O programa é gerenciado pelo Instituto Nacional de Processamento de Embalagens Vazias (inpEV), que realiza a logística reversa das embalagens de agrotóxicos no Brasil. O sistema abrange todas as regiões do país e tem como base o conceito de responsabilidade compartilhada entre agricultores, indústria, canais de distribuição e poder público. Composto por uma rede com mais de 400 unidades de recebimento de embalagens, em 
25 estados brasileiros e no Distrito Federal, gerenciadas por cerca de 260 associações de revendedores se tornou sinônimo de sucesso.

Embora muito recomendadas, as medidas para o descarte seguro nem sempre são seguidas. O que, geralmente, observa-se em campo é o abandono de embalagens nos locais de abastecimento dos pulverizadores, próximo a mananciais de água e a sua reutilização ou venda para outros fins, como o acondicionamento de alimentos (KUNZ, 1992; Mello (2013), ALENCAR et al., 1998).

No Estado de Mato Grosso, compete às secretarias de Estado de Desenvolvimento Rural e Agricultura Familiar, de Meio Ambiente e de Saúde, no âmbito de suas respectivas áreas de competência, a fiscalização do cumprimento da legislação estadual referente a agrotóxicos, resíduos, seus componentes e afins e do que é outorgado pela legislação federal vigente, de acordo com a lei estadual $n$ ㅇ 8858/06.

A coordenação e a execução das atividades relativas ao uso, à produção, ao consumo, ao comércio, ao armazenamento, ao transporte, à aplicação, à fiscalização e ao destino final das embalagens de agrotóxicos, afins e resíduos, no território do Estado de Mato Grosso, previstas nesta lei, terão o apoio da Secretaria de Estado de Fazenda, das polícias Militar, Rodoviária e Civil do Estado de Mato Grosso e das polícias Federal e Rodoviária Federal, através de convênio e/ou termo de cooperação técnica. O cadastro de agrotóxicos e afins trata-se de ato privativo do Indea/MT, que permite comercializar, transportar, armazenar, e utilizar um agrotóxico e afins no Estado de Mato Grosso.

De acordo com a lei no 9.974, de 2000, as embalagens rígidas que contiverem formulações miscíveis ou dispersíveis em água deverão ser submetidas pelo usuário à operação de tríplice lavagem, ou tecnologia equivalente, conforme normas técnicas oriundas dos órgãos competentes e orientação constante de seus rótulos e bulas. Antes do descarte, as empresas produtoras de equipamentos para pulverização deverão, no prazo de 180 dias da publicação desta Lei, inserir nos novos equipamentos adaptações destinadas a facilitar as operações de tríplice lavagem ou tecnologia equivalente. 


\section{Descarte de embalagens}

As empresas produtoras e comercializadoras de agrotóxicos, seus componentes e afins são responsáveis pela destinação das embalagens vazias dos produtos por elas fabricados e comercializados, após a devolução pelos usuários, e também dos produtos apreendidos pela ação fiscalizatória e dos impróprios para utilização ou em desuso, com vistas a sua reutilização, reciclagem ou inutilização, obedecidas as normas e instruções dos órgãos registrantes e sanitário-ambientais competentes (Lei no 9.974, de 2000).

Sendo assim, o agricultor deve preparar as embalagens vazias para devolvê-las nas unidades de recebimento, considerando que cada tipo de embalagem deve receber tratamento diferente. Existem dois tipos de embalagens: laváveis (rigidas) e não laváveis (flexíveis e rígidas). Logo após seu uso, elas devem ser preparadas para a devolução de acordo com o seu tipo.

De forma geral, o descarte de resíduos e de embalagens vazias de agrotóxicos deve ser realizado seguindo o disposto na legislação. Se feito de forma indevida, pode resultar em sérios danos ao homem, aos animais e ao meio ambiente. Os resíduos incluem restos de agrotóxicos, embalagens vazias e produtos contaminados com os agrotóxicos. As embalagens vazias devem ser encaminhadas à central de recebimento da região. A tríplice lavagem dos equipamentos e embalagens é um procedimento que deve ser seguido antes do envio da embalagem ao seu destino. $\mathrm{O}$ mesmo procedimento deve ser efetuado para a limpeza dos equipamentos usados na aplicação de agrotóxicos.

As embalagens vazias devem ser devolvidas com suas tampas e rótulos. $\mathrm{O}$ agricultor pode reunir uma quantidade que justifique $o$ transporte, pois ele tem o prazo de um ano depois da compra para devolver as embalagens vazias. Se sobrar produto na embalagem, poderá devolvê-la até 6 meses após o vencimento.

O sucesso do Brasil ganhou destaque mundial após a criação do sistema campo limpo\InpEV, e os postos de entrega em Mato Grosso também são de responsabilidade do inpEV.

A indústria fabricante recolhe as embalagens nos postos. Se estiverem limpas, depois da lavagem, elas são encaminhadas para 
reciclagem. Se não estiverem limpas, são enviadas para incineradores credenciados. As embalagens não laváveis (cerca de $5 \%$ do total) também são incineradas.

A maioria das embalagens é reciclada e torna-se novos produtos, como tubos para construção civil, bateria de carros ou voltam a ser outra embalagem de agroquímico. O principal motivo para dar destinação final correta às embalagens vazias de agrotóxicos é diminuir o risco à saúde das pessoas e de contaminação do meio ambiente. Apesar de existirem embalagens laváveis e não laváveis, a maioria é lavável, prática de suma importância para devolução e destinação final correta.

\section{Embalagens não laváveis}

São todas as embalagens flexíveis que não utilizam água como veículo de pulverização e as embalagens rígidas. Incluem-se nesta definição as embalagens secundárias não contaminadas rígidas ou flexíveis: sacos plásticos, de papel, metalizados, mistos ou de outro material flexível; Embalagens de produtos para tratamento de sementes, ultrabaixo volume (UBV); Caixas de papelão, cartuchos de cartolina, fibrolatas e embalagens termomoldáveis.

\section{Embalagens laváveis}

São as embalagens rígidas (plásticas, metálicas e de vidro) que acondicionam formulações líquidas de agrotóxicos para serem diluídas em água.

\section{a. Tríplice lavagem}

Para a tríplice lavagem das embalagens de agrotóxicos, deve-se adotar o seguinte procedimento:

- esvaziar a embalagem completamente, deixando o líquido escorrer no tanque do pulverizador; adicionar água limpa até $25 \%$ da capacidade da embalagem; fechar e agitar a embalagem por 30 segundos; verter a água da embalagem no tanque do pulverizador; repetir o procedimento pelo menos mais duas vezes; e perfurar a embalagem para garantir que ela não será reutilizada para outros fins. 


\section{b. Lavagem com pressão}

Logo após o esvaziamento, deve-se encaixar a embalagem em local apropriado instalado no pulverizador, acionar o mecanismo para liberar o jato de água limpa e direcioná-lo para todas as paredes internas da embalagem por 30 segundos. A água da lavagem deve ser transferida para o interior do tanque do pulverizador. Após isso, deve-se inutilizar a embalagem plástica ou metálica, perfurando o fundo, e armazenar em local apropriado até o momento da devolução.

\section{Descarte de produtos}

A aplicação de um produto fitossanitário deve ser planejada de modo a evitar desperdícios e sobras. É de suma importância o cálculo da dosagem a ser aplicada em função da área a ser tratada.

Caso ocorra sobra da calda no tanque do pulverizador, esse volume deverá ser recalculado para evitar que ocorra novamente. A sobra deve ser diluída em água e aplicada nas bordaduras da área tratada ou nos carreadores. Se o produto for um herbicida, repassá-lo em áreas tratadas poderá causar fitotoxicidade, por isso deve ser evitado. As sobras ou restos de produtos não devem ser jogados em rios, lagos ou demais coleções de água (EMBRAPA, 2005).

Quando sobrar um produto concentrado, ele deverá ser mantido em sua embalagem original, que deve estar fechada adequadamente. $\mathrm{O}$ armazenamento deve ser em local seguro e segregado. Caso o produto esteja vencido, impróprio para uso ou em desuso, a empresa registrante deverá ser consultada por meio do número de telefone indicado no rótulo para sua devolução e destinação final.

No caso de aviação agrícola, o processo e regido conforme instrução normativa 2/2008. Essa instrução traz que, os eventuais restos de agrotóxicos remanescentes no avião e as sobras da lavagem e limpeza da aeronave ou dos equipamentos de apoio no solo somente poderão ser descartados em local apropriado, o pátio de descontaminação, observados os modelos próprios, aprovados pelo Mapa, ou sobre a mesma lavoura tratada, desde que diluídos na maior quantidade de água possível. A empresa de 
aviação agrícola, pessoa física ou jurídica, deverá possuir pátio de descontaminação de acordo com o modelo existente, obedecendo às regras, como por exemplo:

I - o pátio de descontaminação das aeronaves agrícolas deverá ser construído sob orientação de técnico habilitado, em local seguro, quanto à operação aeronáutica e à contaminação ambiental;

II - deverá ser feita sondagem no local da construção, para determinação do nível do lençol freático, que não deve estar a menos de um metro e meio da superfície;

III - o piso do pátio de descontaminação das aeronaves agrícolas deverá obedecer às especificações próprias;

IV - o sistema coletor do pátio de descontaminação da água de lavagem das aeronaves agrícolas deverá ser situado no meio do pátio, conduzir o produto proveniente da limpeza através de canaleta ou de caixa coletora por tubulação para o reservatório de decantação, passando pela caixa de inspeção; e a tubulação para o reservatório de decantação deve dispor de sistema de derivação da água das chuvas.

V - o reservatório de decantação para recepção da água de lavagem proveniente da canaleta ou da caixa coletora deverá ser construído com dois tubos de concreto armado, com diâmetro de um metro e profundidade de dois metros, sendo que a base do poço será fechada com camada de concreto armado com espessura de 10 centímetros e o cimento utilizado deverá ser padrão Fck $25 \mathrm{Mpa}$ ou superior, na proporção de $450 \mathrm{~kg}$ de cimento por metro cúbico de concreto, perfeitamente alisado e recoberto com manta impermeabilizante e deve ser fechado com tampa de concreto;

$\mathrm{VI}$ - o sistema de oxidação de agrotóxicos da água de lavagem das aeronaves agrícolas deverá conter: sistema de bombeamento para a retirada da água de lavagem das aeronaves do reservatório de decantação e envio desta ao reservatório de oxidação; ozonizador com capacidade mínima de produzir um grama de ozônio por hora; reservatório para oxidação que deverá ter capacidade mínima de 500 litros, ser em policloreto de vinila (PVC), para que não ocorra reação com o ozônio, ser redonda, para facilitar a circulação da água de lavagem, com tampa para evitar contato com a água de lavagem; e as canalizações, que deverão ser em tubo PVC, 
para que não ocorra reação com o ozônio, e com diâmetro de 50 milímetros.

VII - o ozonizador previsto na alínea b, do inciso anterior, deverá funcionar por um período mínimo de seis horas, para cada carga de 450 litros de restos e sobras de agrotóxicos remanescentes da lavagem e limpeza das aeronaves e equipamentos; VIII - dentro do reservatório de oxidação, deverá ser instalada a saída do ozonizador, na sua parte inferior, para favorecer a circulação total e permanente da água de lavagem e com dreno de saída na parte superior do reservatório de oxidação; IX - o reservatório de retenção, solarização e de evaporação da água de lavagem das aeronaves agrícolas deverá ser: devidamente impermeabilizado com gelmembrana, polietileno de alta densidade (Pead) de um milímetro de espessura, cercado, sinalizado e situado preferencialmente em local com distância mínima de $\mathbf{2 5 0}$ metros de mananciais hídricos, e distantes de árvores para facilitar a solarização, gerando um aumento da degradação via fotólise do material que tenha ficado retido no fundo do tanque; aberto ou com cobertura, e deverá possuir as dimensões, em função do número de aeronaves. $X$ - na escolha de tipo coberto, cuja função é evitar o acúmulo de água das chuvas, a estrutura do telhado será com pé-direito de um metro e a cobertura terá sua parte externa pintada da cor preta, com objetivo de aumentar as temperaturas internas do tanque e do efluente ali retido, potencializando sua evaporação;

XI - fica vedada a utilização de telhas de amianto;

XII - ao redor do reservatório de retenção, deverá ser construída uma proteção para evitar entrada de água por escorrimento superficial; e

XIII - o sistema de segurança do reservatório de retenção e evaporação deverá conter obrigatoriamente placas indicativas, em locais visíveis, com o símbolo internacional que represente produtos tóxicos e perigo.

Qualquer alteração na construção do pátio de descontaminação e no seu sistema de descontaminação das aeronaves deverá ser previamente aprovada pelo Mapa.

Parágrafo único. A alteração prevista no caput só será aprovada mediante a apresentação de projeto específico com as devidas anotações de responsabilidades técnicas (Lei no 9974/2000). 


\section{Segurança e organização no armazenamento}

O armazenamento de agrotóxicos, seus componentes e afins obedecerá à legislação vigente, Decreto no 4.074 (04/01/2002) - Capítulo V, Seção I e às instruções fornecidas pelo fabricante, inclusive especificações e procedimentos a serem adotados no caso de acidentes, derramamento ou vazamento de produto e, ainda, às normas municipais aplicáveis, inclusive quanto à edificação e à localização.

A ABNT 9843/2004, ABNT 9843/2013, NR 23/2011e ABNT 14725:4/2012 estabelecem regras para o armazenamento adequado desses agrotóxicos, dentre elas local de armazenamento, critérios de construções, proteção contra incêndios e ficha de informação de segurança de produtos químicos (FISPQ), saúde e meio ambiente. Trata-se de um conjunto de normas que se aplicam a propriedades rurais, empresas e prestadoras de serviço, quando localizadas em área rural.

Ficha de Informação de Segurança de Produto Químico|FISPQ (ABNT NBR 14725:4 - 2012) é um meio de o fornecedor transferir informações essenciais sobre os perigos de um produto químico (incluindo ações de emergência) ao usuário deste FISPQ possibilita tomar as medidas necessárias relativas à segurança, saúde e meio ambiente. Também fornecerá conhecimentos básicos sobre os produtos químicos, recomendações sobre medidas de proteção e ações em situação de emergência a trabalhadores, empregadores, profissionais da saúde e segurança, pessoal de emergência, agências governamentais, assim como membros da comunidade e outras partes envolvidas com o produto químico. 
FICHA DE INFORMAÇÕES DE SEGURANÇA

DE PRODUTO QUÍMICO

NOME DO PRODUTO

1. IDENTIFICAÇÃO DO PRODUTO E DA EMPRESA

2. COMPOSIÇĀO E INFORMAÇŌES SOBRE OS INGREDIENTES

3. IDENTIFICAÇÃO DE PERIGOS

4. MEDIDAS DE PRIMEIRO SOCORROS

5. MEDIDAS DE PREVENÇÃO E COMBATE A INCÊNDIO

6. MEDIDAS DE CONTROLE PARA DERRAMAMENTO OU VAZAMENTO

7. MANUSEIO E ARMAZENAMENTO

8. CONTROLE DE EXPOSIÇÃO E PROTEÇÃO INDIVIDUAL

9. PROPRIEDADES FÍSICO-QUÍMICAS

10. ESTABILIDADE E REATIVIDADE

11. INFORMAÇÕES TOXICOLÓGICAS

12. INFORMAÇÕES ECOLÓGICAS

13. CONSIDERAÇÕES SOBRE TRATAMENTO E DISPOSIÇÃO

14. INFORMAÇÕES SOBRE TRANSPORTE

15. REGULAMENTAÇŌES

16. OUTRAS INFORMAÇÕES

No mesmo local de armazenamento de agrotóxicos e afins nas propriedades rurais será admitida a guarda de pulverizador costal e seus acessórios. Devem ser consideradas também as legislações locais, inclusive de municípios, muitas vezes estabelecem detalhes, especialmente quanto à localização dos armazéns de produtos perigosos naquela referida região.

O depósito (nome designado ao espaço físico para guardar, estocar, conter e manter agrotóxicos e afins em condições que garantam a saúde e segurança do trabalhador, ambiental e dos produtos na propriedade rural) deve estar em local livre de inundações, separado de locais de estoque e/ou manuseio de alimentos, medicamentos e instalações para animais e mantendo distância de moradias e cursos naturais de água. 
Requisitos para construção do depósito de agrotóxicos na propriedade rural:

- Ser exclusivo para produtos agrotóxicos e afins;

- Ter altura que possibilite ventilação e iluminação;

- Possuir ventilação comunicando-se exclusivamente com o exterior e dotada de proteção que não permita o acesso de animais;

- Ser construído em alvenaria e/ou material que não propicie a propagação de chamas (todos os empregadores devem adotar medidas de prevenção de incêndios, em conformidade com a legislação estadual e as normas técnicas aplicáveis);

- Quando construído parede-parede com outras instalações, a separação não pode possuir elementos vazados, permitindo o acesso restrito ao depósito pelo interior de outras instalações;

- Deverão dispor de saídas, em número suficiente e dispostas de modo que aqueles que se encontrem nesses locais possam abandoná-los com rapidez e segurança, em caso de emergência;

- Ter piso que facilite a limpeza e não permita infiltração;

- Ter sistema de contenção de resíduos no próprio depósito, por meio da construção de lombadas, muretas, desnível de piso ou recipiente de contenção e coleta;

- Possuir instalações elétricas, quando existentes, em bom estado de conservação para evitar acidentes;

- No caso de armazenamento de agrotóxicos e afins em quantidade até 100 litros ou $100 \mathrm{~kg}$, admite-se o uso de armário exclusivo e trancado para material que não propague chamas, abrigado fora de residências, alojamentos para pessoas ou animais, escritórios, ambientes que contenham alimentos e rações;

- Admite-se o uso de estantes ou prateleiras para acondicionamento de agrotóxicos e afins às quais poderão estar fixadas nas paredes, desde que não interrompam as saídas de emergência e rotas de fuga. Os produtos devem manter uma distância mínima de 0,10 $\mathrm{m}$ das paredes, armazenados isolados do piso. 


\section{Requisitos de segurança no deposito:}

- Utilizar equipamento de proteção individual (EPI) apropriado;

- Seguir as informações de manuseio com base no rótulo e bula do produto;

- Possuir, afixada no depósito, placa de sinalização com os dizeres "cuidado veneno";

- Ter acesso restrito aos trabalhadores devidamente orientados a manusear e manipular os agrotóxicos e afins;

- Manter embalagens acondicionadas em recipiente lacrado e identificado, em caso de embalagens danificadas ou com vazamentos de produto, estas devem ser recondicionadas em recipiente lacrado e identificado, guardadas no próprio depósito, e deve-se comunicar ao fabricante;

- Recolher os resíduos com material absorvente, como serragem, areia ou similares, e comunicar ao fabricante em caso de vazamento ou derreamento de agrotóxicos e afins;

- Segregar e identificar produtos vencidos ou embalagens com sobras de produtos e guardá-los no mesmo depósito até serem recolhidos pelo fabricante;

- Fechar e lacrar as embalagens com as tampas voltadas para cima, seguindo as demais orientações de acondicionamento e manuseio do fabricante, de acordo com ABNT NBR-7500;

- Armazenar as embalagens com as identificações ou rótulos à vista;

- Armazenar as embalagens vazias de agrotóxicos e afins, laváveis e não laváveis, no mesmo depósito, desde que segregadas das demais embalagens e em acordo com as orientações do fabricante;

- Utilizar equipamento de refrigeração exclusivo para o armazenamento dos produtos agrotóxicos biológicos dentro do depósito.

* Definição de área segregada: local físico, reservado, sinalizado e identificado para a finalidade específica, de acordo com o sistema de controle utilizado. 


\section{EMPILHAMENTO DAS EMBALAGENS NO ARMAZÉM:}

- $\operatorname{Sacos}=45$ sacos/estrado $(1,2 \times 1,2 \mathrm{~m})$, cuidado com deslizamento dos sacos,

- $\quad$ Baldes = 4/pilha,

- Caixas coletivas (fab.) = (acatar a altura máxima de empilhamento indicada nos volumes, de acordo com cada fabricante).

- Tambores:

- $\quad-<601=2 /$ pilha,

- $\quad$ - 200 I = não empilhar

\section{Boas práticas de manejo}

No que se diz respeito ao controle de pragas, doenças e plantas invasoras o manejo integrado pode trazer impactos positivos na produção e para o agroecossistema em geral. Desta forma se torna fundamental o conhecimento e equilíbrio entre o controle químico, biológico, físico, mecânico, cultural, genético, etc. É preciso analisar também o risco benefício do uso de qualquer produto químico. Nesse contexto, as boas práticas de manejo (BPMs) referem-se às práticas que ajudam a reduzir o risco potencial de o agroquímico ser transportado pela água e atingir o lençol freático ou as águas subterrâneas que abastecem os municípios e a contaminação de pessoas e animais. As BPMs relacionadas a seguir, quando incorporadas às operações regulares na condução da lavoura, podem contribuir para reduzir o impacto indesejável resultante da utilização de agrotóxicos ao meio ambiente e à saúde humana. Objetivos: produção de alimentos saudáveis, melhoria da saúde do trabalhador e preservação e saúde do meio ambiente.

\section{Saúde do Meio Ambiente e Crimes Ambientais}

De acordo com a Constituição federal, Capítulo VI, DO MEIO AMBIENTE: todos têm direito ao meio ambiente ecologicamente equilibrado, bem de uso comum do povo e essencial à sadia qualidade de vida, impondo-se ao Poder Público e à coletividade o dever de defendê-lo e preservá-lo para as presentes e futuras gerações. 
Cabe ao poder público exigir na forma da lei, para instalação de obra ou atividade potencialmente causadora de significativa degradação do meio ambiente, estudo prévio de impacto ambiental, a que se dará publicidade; controlar a produção, a comercialização e o emprego de técnicas, métodos e substâncias que comportem risco para a vida, a qualidade de vida e o meio ambiente. As condutas e atividades consideradas lesivas ao meio ambiente sujeitarão os infratores, pessoas físicas ou jurídicas, a sanções penais e administrativas, independentemente da obrigação de reparar os danos causados. A lei de crimes ambientais (Lei № 9.605/98) dispõe sobre as sanções penais e administrativas derivadas de condutas e atividades lesivas ao meio ambiente, e dá outras providências. Sendo assim, no que se refere a poluição e outros crimes ambientais, causar poluição de qualquer natureza em níveis tais que resultem ou possam resultar em danos à saúde humana, ou que provoquem a mortandade de animais ou a destruição significativa da flora, a pena será reclusão (de um a quatro anos), e multa. Também se caracteriza como crime produzir, processar, embalar, importar, exportar, comercializar, fornecer, transportar, armazenar, guardar, ter em depósito ou usar produto ou substância tóxica, perigosa ou nociva à saúde humana ou ao meio ambiente, em desacordo com as exigências estabelecidas em leis ou nos seus regulamentos resulta em pena de reclusão (um a quatro anos), e multa. Na mesma pena, incorre quem: abandona os produtos ou substâncias referidos no caput ou os utiliza em desacordo com as normas ambientais ou de segurança, quem manipula, acondiciona, armazena, coleta, transporta, reutiliza, recicla ou dá destinação final a resíduos perigosos de forma diversa da estabelecida em lei ou regulamento (Incluído pela Lei no 12.305, de 2010).

Construir, reformar, ampliar, instalar ou fazer funcionar, em qualquer parte do território nacional, estabelecimentos, obras ou serviços potencialmente poluidores, sem licença ou autorização dos órgãos ambientais competentes, ou contrariando as normas legais e regulamentares pertinentes também resulta em pena de detenção (um a seis meses), ou multa, ou ambas as penas cumulativamente. As penalidades previstas somente serão aplicadas se do fato não resultar crime mais grave e podem variar de acordo com outros fatos previstos em lei. 


\section{CONSIDERAÇÕES FINAIS}

A gestão ambiental tem sido apontada como uma área de grande valor, para o desenvolvimento da sociedade humana, especialmente na premissa de proteger o meio ambiente no que diz respeito aos impactos ambientais decorrentes das atividades humanas. Nesse contexto, a realidade no campo não é diferente, onde as demandas são cada vez maiores e se busca um equilíbrio para o desenvolvimento sustentável, tanto da cadeia agrícola quanto do bem-estar do trabalhador no campo e do ecossistema, com uso correto de produtos químicos.

\section{REFERÊNCIAS}

AGRICULTURA RURAL. Saiba como Funciona o Sistema de Devolução de Embalagens de Agrotóxicos. 2013. Disponivel em: <http://www.canalrural.com. br/noticias/agricultura/saiba-como-funciona-sistema-devolucao-embalagens-agrotóxicos-27874>. Acessado em: 29 de julho de 2015.

ALENCAR, J. A. et al. Descarte de Embalagens de Agrotóxicos. Revista Ecotoxicologica e Meio Ambiente, v. 8, n.1, p. 9-25, jan./dez., Curitiba, 1998.

ANDEF. Manual de boas práticas no uso de EPIs. São Paulo. ANDEFedu, 2013.

Associação Brasileira de Normas Técnicas. ABNT 14725:4/2010. Ficha de informação de segurança de produtos - FISPQ.

Associação Brasileira de Normas Técnicas. ABNT 14725-1. Terminologia.

Associação Brasileira de Normas Técnicas. ABNT 9843/2004. Armazenamento de agrotóxicos e afins.

Associação Brasileira de Normas Técnicas. ABNT 9843-3:2013. Agrotóxico e afins (Parte 3: Armazenamento em propriedades rurais).

Associação Brasileira de Normas Técnicas. ABNT NBR 13.968. Embalagem rígida vazia de agrotóxico - Procedimentos de lavagem.

Associação Brasileira de Normas Técnicas. ABNT NBR 14725:4 - 2012. Ficha de segurança - FISPQ.

Associação Brasileira de Normas Técnicas. ABNT NBR 9735. EPI para transporte terrestre produtos perigosos.

BRASIL. Decreto no 4.074/2002 - Regulamenta a Lei $n^{\circ} 7.802$, de 11 de julho de 1989.

BRASIL. Instrução Normativa 2 -. Diário Oficial da União. Brasília, DF. Seção I, p. 5, 2008. 
BRASIL. Lei Federal 7.802 de 11 de julho de 1989 - Lei dos agrotóxicos.

BRASIL. Lei Federal 9.605 de 12 de fevereiro de 1998 - Lei de Crimes Ambientais.

BRASIL. Lei Federal 9.974 de 6 de junho de 2000 - Altera a Lei $n^{\circ} 7.802$

BRASIL. Lei Federal 12.305 de 2010 - Altera a Lei $n^{\circ} 7.802$

BRASIL. Norma Regulamentadora do Ministério do Trabalho e Emprego. NR 06/2014 - - equipamento de proteção individual - EPI. Disponível em: <http:// portal.mte.gov.br/data/files/FF8080814CD7273D014D34C6B18C79C6/NR-06\%20 (atualizada)\%202015.pdf >. Acessado em: 29 de julho de 2015.

BRASIL. Norma Regulamentadora do Ministério do Trabalho e Emprego. NR 23/2011 -Proteção contra incêndios. Disponível em: http://portal.mte.gov.br/ data/files/8A7C816A2E7311D1012FE5B554845302/nr 23 atualizada 2011.pdf. Acessado em: 29 de julho de 2015.

BRASIL. Norma Regulamentadora do Ministério do Trabalho e Emprego. NR 31/2013 - Norma Regulamentadora de Segurança e Saúde no Trabalho na Agricultura, Pecuária, Silvicultura, Exploração Florestal e Aquicultura. Disponível em: http://portal.mte.gov.br/data/files/8A7C816A4295EFDF0143067D95BD746A/ NR-31\%20(atualizada\%202013).pdf. Acessado em: 29 de julho de 2015.

CAMPANHOLA, C.; BETTIOL, W. Panorama sobre o uso de agrotóxicos no Brasil. In: Programa de Defesa Ambiental Rural. 1a Ed., v. 1. p. 7-26. Fórum Nacional de Secretários de Agricultura. Brasília, 2002.

COMPANHIA DA TERRA. Devolução de embalagens. 2007. Disponivel em http:// www.companhiadaterra.com.br/embalagem.php. Acessado em: 12 dez. 2013.

COMPANHIA NACIONAL DE ABASTECIMENTO. 8 Levantamento - Safra 2016/2017

-Grãos. Disponivel em: < http://www.conab.gov.br/conteudos.php?a=1253\&t=2> . Acesso em: 05 jun. 2017

EMPRESA BRASILEIRA DE PESQUISA AGROPECUARIA/EMBRAPA, 2005. Disponívelem:<http://sistemasdeproducao.cnptia.embrapa.br/FontesHTML/Uva/MesaNorteMinas/normas.htm. Acesso em Jun 2017.

FAIRBANKS, M. Agrotóxicos ampliam o mercado. Revista Química e Derivados. São Paulo 396:398-403. 2001.

INSTITUTO BRASILEIRO DE GEOGRAFIA E ESTATÍSTICA. Levantamento Sistemático da Produção agrícola. Disponível em: $<$ http://www.ibge.gov.br/home/estatistica/ indicadores/agropecuaria/lspa/default.shtm>. Acesso em: 01 jun. 2017.

INSTITUTO NACIONAL DE PROCESSAMENTO DE EMBALAGENS VAZIAS - inpEV. Institucional. Disponível em: http://www.inpev.org.br/institucional/inpev/inpev. asp. Acesso em 08 jun. de 2015.

INSTITUTO NACIONAL DE PROCESSAMENTO DE EMBALAGENS VAZIAS - inpEV. Relatorio de sustentabilidade 2016. Disponível em: http://www.inpev.org.br/ 
relatorio-sustentabilidade/2016/pt/index.html. Acesso em 26 jul. de 2017.

INSTITUTO NACIONAL DE PROCESSAMENTO DE EMBALAGENS VAZIAS (inpEV). Institucional. Disponivel em: $<$ http://www.inpev.org.br/institucional/inpev/inpev. asp >. Acesso em 08 maio 2010.

KOOP, B. L.; SCHAINHUK, L.; LEANDRINI, J. A. Agrotóxicos. ANAIS do II SEPE Seminário de Ensino, Pesquisa e Extensão da Universidade Federal da Fronteira Sul - UFFS. Anais... 2013.

LAMBERT, D.; STOCK, J. Strategic Physical Distribuition Management. Homewood, IL: Irwin, 1981.

LEITE, P. R. Logística Reversa: meio ambiente e competitividade. São Paulo: Pearson Prentice Hall, 2009.

LIDWIEN, A. M.; SMITH, B. N.; VAN WENDEL, D. J. Neurological symptoms among Sri Lanka farmers occupationally exposed to acetyl cholinesterase-inhibiting insecticides. American Journal of Industrial Medicine. Malden MA 44:254-64. 2003.

MATO GROSSO. Lei 8588/2006 de 27 de novembro de 2006. Disponível em: http://app1.sefaz.mt.gov.br/0325677500623408/07FA81BED2760C6B84256710004D3940/73C898B81266D3D504257234006B94D9. Acessado em: 28 de julho de 2015.

MELLO, C. M.; SILVA, L. F.; Fatores associados à intoxicação por agrotóxicos: estudo transversal com trabalhadores da cafeicultura no sul de Minas Gerais. Epidemiol. Serv. Saúde, Brasília, v. 22, n. 4, p. 609-620, out./dez., 2013.

OLIVEIRA, A. A.; SILVA, J. T. M. A Logística Reversa no Processo de Revalorização dos Bens Manufaturados. REA, Revista Eletrônica de Administração [online], v. 4, n. 2, 2005. Disponível em: http://periodicos.unifacef.com.br/index.php/rea/ article/view/191 >. Acesso em: 19 jul. 2013.

PANTALEÃO, F. S. EPI - Equipamento de Proteção Individual - Não Basta Fornecer, é Preciso Fiscalizar. Disponível em: http://www.guiatrabalhista.com.br/tematicas/ epi/htm. Acessado em: 29 de julho de 2015.

SAADEH, A. M.; ALALY, M. K.; FARSAKH, N. A.; et al. Clinical and sociodemographic future of acute carbamate and organophosphate poisoning: a study of adult patients in north Jordan. J. Toxicol Clin. Toxicol. San Francisco. 34:45-51. 1996.

SENANAYAKE, N.; PEIRES, H. Mortality due to poisoning in a developing agricultural country: trends over 20 years. Hum Exp. Toxicol. San Francisco. 14:808-11. 1995.

SOTH, T.; HOSOKAWA, M. Organophosphate and their impacts on the global environment. Neurotoxicology. Atlanta. 21:1-4. 2000.

VEIGA, M. M. Agrotóxicos: eficiência econômica e injustiça socioambiental. Revista Ciência Coletiva, v. 12, p. 145-152, 2007. 